\section{The autonomy of informal STEM and benefits of andragogy with gifted children}

\author{
Julia E. Calabrese and Robert M. Capraro \\ Teaching, Learning and Culture, Texas A\&M University System, College Station, \\ Texas, USA
}

Autonomy of informal STEM

Received 22 August 2021 Revised 23 November 2021 Accepted 23 November 2021

\begin{abstract}
Purpose - In distinguishing the education of adults from the education of children, a gray area lies on where to classify gifted and honors students. The purpose of this study was to determine if the attitudes of students at an honors STEM summer camp paralleled the educational needs of adults, namely self-directed learning.

Design/methodology/approach - Researchers analyzed survey responses through an exploratory factor analysis and five $t$ tests.

Findings - The interpretation of the effect sizes showed that after engaging in a self-directed learning experience, students expressed more positive self-efficacy and intrinsic motivation, experienced reduced extrinsic motivation and anxiety, and were less task-completion oriented.

Originality/value - The results suggest that gifted and honors students may have a propensity to learn that is more similar to that of adults rather than their same-age peers.
\end{abstract}

Keywords andragogy, Gifted students, Informal STEM education

Paper type Research paper

It may seem logical to some that gifted students have different educational needs than the average learner. Gifted students' mental, emotional and social developmental stages are often less symmetric than their peers (Bailey, 2007). They are typically aware of their differences and unfortunately make an attempt to hide them. Often this comes in the form of strategically underperforming academically in an attempt to "blend in" while still claiming a satisfactory grade (O'Boyle, 2008). Though they may attempt to blend in, prior research has shown that gifted students prefer different learning styles than their non-gifted same-age peers (Kahyaoglu, 2013). To help teachers better educate these students, it is important to understand just how gifted students may be impacted by non-traditional approaches to education, including andragogy and informal learning. While it is possible to find research on andragogy, gifted learners and informal learning separately, we could find no existing research that connects all three. Informal learning has often been connected to andragogy in previous studies (e.g. Livingstone, 2001; Rogers, 2014), but there is little research on gifted students and informal learning. Because there are no current studies linking informal STEM, gifted students and andragogy, we investigated the nature of the changes in attitude toward learning that could be attributable to the planned and integrated use of andragogy with honors students in an informal setting.

(C) Julia E. Calabrese and Robert M. Capraro. Published in Journal of Research in Innovative Teaching \& Learning. Published by Emerald Publishing Limited. This article is published under the Creative Commons Attribution (CC BY 4.0) licence. Anyone may reproduce, distribute, translate and create derivative works of this article (for both commercial and non-commercial purposes), subject to full attribution to the original publication and authors. The full terms of this licence may be seen at http:// creativecommons.org/licences/by/4.0/legalcode



Journal of Research in Innovative Teaching \& Learning Vol. 15 No. 2, 2022 pp. 207-217
Emerald Publishing Limited 2397-7604 DOI 10.1108/JRIT-08-2021-0060 
JRIT

15,2

208

\section{Relevant literature}

Pedagogy versus andragogy

Most educators are familiar with the term pedagogy, but fewer are familiar with the idea of andragogy. The common understanding is that pedagogy is synonymous with teaching (Knowles, 1996). However, as the field of education developed, there became a need to distinguish between the best strategies for educating children from those for educating adults (Alderman, 1928; Merriam, 2001). During the early stages of adult education, teachers made little to no differentiation between their existing practices, developed for teaching children, when teaching adults. Unfortunately, many felt this was an inadequate approach, and many adult learners left their learning programs (Knowles, 1980). To address this problem, the new term "andragogy" was coined in an attempt to designate a separate teaching style geared toward adults (Merriam, 2001). Still, many are unfamiliar with what separates the two approaches of pedagogy and andragogy.

A key difference in distinguishing traditional (pedagogical) and andragogical techniques is the way knowledge is obtained. Specifically, traditional techniques such as lecture and rote memorization, even assessment methods, all rely on direct transmission of information (Knowles, 1980). Though adult learning had been slowly developing since the 1920s (Merriam, 2001), Malcom Knowles played a large role in the development of andragogy during the 1970s and 1980s by using his own experiences with adult education. The prominent perspective of Knowles' theory is to allow the learner to have more autonomy in their learning while reducing the responsibility of the instructor. Information was no longer transferred directly; rather, the learner obtained it themselves (Henschke, 2011). This stemmed from the adult's natural desire to control their own lives, which had been previously enabling their desire to revolt against traditional instruction (Knowles, 1996). This new approach allowed adult students to make their own decisions in education as they already were in other aspects of life (Merriam, 2001). This self-directed form of learning separated them from children.

\section{Gifted learners}

Children classified as gifted or honors make for complex students. On one hand, they tend to exhibit greater imagination and resourcefulness than their same-age peers (Warren and Heist, 1960). They also tend to hold high expectations, both for themselves and others. However, despite their strong abilities, they are keenly aware of their differences, often precipitating a negative self-image (Neihart et al., 2002). They may undervalue their own achievements that may have met others' standards but fell short of their own (Bailey, 2007). They possess a strong desire to appear the same as their peers while still pleasing their parents and/or teachers (O'Boyle, 2008). Thus, they may exhibit more inhibitions than their peers and even feel as though they are generally not accepted (Neihart et al., 2002). The full spectrum of their exceptionality may make it difficult for teachers to address the needs of gifted students successfully without proper training.

In light of the qualities that separate them from their peers, it is important to consider how gifted children may learn differently. In terms of learning, research has shown that they also share many qualities with adults in terms of learning needs (Ricca, 1984). After all, gifted children tend to be more socially and emotionally mature than their peers (Neihart et al.,2002). In fact, their intellectual age may actually be higher than their biological age (Bailey, 2007). For instance, they possess higher levels of motivation and responsibility (Ricca, 1984) and higher processing abilities (Carnicom and Clump, 2004). They also tend to get bored with routine or less challenging activities. This can result in poor behavior and general issues in the classroom setting (Bailey, 2007; Park and Oliver, 2009). Finally, they share and desire a higher level of independence in their learning (Ricca, 1984). It is quite possible that gifted 
learners may learn more similarly to adults than to their same-age peers. Our purpose for this paper is to begin the conversation and investigation into the use of principles of andragogy with gifted secondary students, specifically situated in informal settings what are apart from standard accountability systems. Prior research has shown that gifted students generally have a positive attitude toward learning mathematics (Erdogan and Yemenli, 2019); however, there is no research connecting gifted students' feelings toward learning via andragogy. In this paper, we aim to investigate honors students' attitudes toward learning discrete mathematics and analytic geometry under andragogical principles.

\section{Informal learning}

It is important to emphasize the variety of environments in which students can learn. When the word "learning" is used, many may picture a classroom or training situation with a strict curriculum and grading process. However, this is only one type of learning that is most often found in traditional K-12 US schools and is known as formal learning (Cross, 2011). In addition to formal learning, there is, of course, informal learning. Informal learning is typically less structured and not constrained by accountability measures. For example, informal learning may include academic coaching (Marsick and Watkins, 2001) and take place in non-classroom environments, such as camps (Ghadiri Khanaposhtani et al., 2018), museums, clubs, zoos (Fenichel and Schweingruber, 2010) and even at home (authors, in press). Informal learning is often self-directed and collaborative (Cross, 2011). Specialized instruction for gifted students has experienced a renaissance of sorts; however, such students are still more likely to encounter individualized work and more emphasis on teacher-directed learning (Khazanchi and Khazanchi, 2020). Gifted students' intellectual development greatly differs from that of their peers however (Neihart et al., 2002), and so traditional pedagogical methods may not be appropriate for them. According to Knowles' theory of andragogy, as students mature, they tend to favor self-directed learning (Merriam, 2001), a quality more common in informal learning, and gifted students are often more mature than their peers (Bailey, 2007; Neihart et al., 2002). While formal learning may be the more traditional image of education, it may not be as effective for more mature learners as informal instruction, which acknowledges the ability of the individual to learn while immersed in the world around them in a self-directed way.

Results from prior research have shown many ways in which informal settings can contribute to the development of learning. A collective environment can help students develop a sense of responsibility (Can et al., 2017) and provides an opportunity for them to contribute to each other's learning processes (Ghadiri Khanaposhtani et al., 2018). The selfdirected nature of informal learning allows students to develop the ability to learn on their own, which can then transfer into their in-school learning experience (Paris, 1997). Additionally, this same quality appeals to adult learning, as it allows adult students to utilize their life experiences (Brockett and Hiemstra, 2018). Informal learning creates an opportunity for a holistic and active learning experience rather than a restrictive, passive one.

Informal learning may be especially beneficial in STEM subjects. For instance, students attending STEM summer camps have reportedly experienced positive changes in attitudes toward mathematics in addition to developing a deeper understanding of mathematical concepts (Can et al., 2017). Similar studies on science camps have reported how the informal setting increased students' interest in science (e.g. Ghadiri Khanaposhtani et al., 2018). Furthermore, STEM camps provide students with opportunities to explore STEM fields in ways they would not experience in the typical classroom (Vela et al., 2020). When students are able to enter professional labs and explore STEM concepts outside of the traditional classroom, they see additional applications of the material that they miss in traditional settings (Roberts et al., 2018). By incorporating informal learning into STEM curricula,
Autonomy of informal STEM 
JRIT

15,2

educators can open the doors to a new STEM world for students. However, although researchers have found that informal learning benefits adults, it may not necessarily have this effect on gifted students, who can be described as being somewhere in between adults and their same-age peers. This study seeks to address a gap in the research by studying how gifted students' attitudes toward learning are influenced by informal learning settings.

\section{0}

\section{Theoretical framework}

The present study took place at a project-based learning (PBL)-oriented STEM summer camp. In this informal learning setting, students engaged in STEM PBL, which Capraro and Slough (2013) define to be an "ill-defined task with a well-defined outcome" (p. 2), by working in groups to accomplish common goals. This style of learning encouraged socialization and communication and is based in social constructivism. In social constructivism, students learn through the combination of their individual previous experiences (Pritchard, 2017). Because the students were from many different locations with varying backgrounds, there was a wide variety of experiences to offer. Rather than relying heavily on the instructor, information was obtained through the students' peer collaboration. Under social constructivism, student learning is obtained through interaction with one another. Humans assimilate what they learn through social contexts and internalize them to form their understanding (Ernest, 2010). This idea was also expressed by Vygotsky (1978), who stated that learning is first an external then internal process. This can occur via social activities such as conversations or play. In the context of the present study, the students relied heavily on group discussions. The instructors merely facilitated the experience as the students took collective responsibility for their learning.

\section{Method}

Participants

The participants in the present study were those students attending a competitive STEM honors camp located at a large research university in the southwestern United States. The camp had an open application process but was not open admission. As part of the admission process, students applying for the honors camp were required to complete an application and entrance exam and meet certain grade standards for mathematics and science course requirements. The application contained three parts: students had to submit two essays — one expressing general interest in the camp and one discussing their interest in entering a career in a STEM field - and they had to submit a letter of recommendation from a teacher and from a community member. In total, 18 students were admitted, representing about $16 \%$ of the applicant pool.

All students participating in the camp had to be entering the 10th, 11th or 12th grade and had to have completed a course in physics and Algebra II or precalculus. Most participants were from the United States, though two were international students. We had students from as far away as a Colombia and Italy and from four different states of the United States. Participants were asked to self-classify and self-report on items such as race, ethnicity, gender and other variables. For this study, only race, gender and ethnicity were of interest. The composition of the 18 students admitted was $55 \%$ White, $20 \%$ Hispanic or Latino, $20 \%$ Asian, and 5\% Black or African American. There were eight female students and 12 male students.

\section{Intervention}

Over two weeks, the participants experienced numerous STEM academic learning activities and additional related activities. On weekdays, students participated in activities designed to build insights into discrete mathematics, smart system structures and geospatial understandings. After the academic portion of the day, students attended a panel session hosted by professionals in various STEM fields. Additionally, the students visited various labs 
on campus, including a rainfall simulator, the veterinary school's surgical and physiology labs, and the ergonomic center. The typical day comprised a hearty STEM schedule balanced with several opportunities for socialization and cultivation of 21st century skills.

In this quasi-experimental pretest-posttest design, students participated in a discrete mathematics experience. The experience was designed by the researcher, who is a former secondary mathematics teacher, and an undergraduate preservice teacher. The activities lasted for 90 min each day for 10 days. On the first day, students were divided into small groups based on ability level, which was predetermined by a pretest assessment of their trigonometry and logical reasoning skills. While the group was as homogeneous as possible from the onset, there were still clear distinctions and strengths among the participants. Based on students' pretest scores, the students were grouped by ability. The top six students were first placed in separate groups. Then, the next six students were evenly placed among the six existing groups. This process repeated until all of the students were placed into groups. As such, each group had students of varying ability and the groups as a whole were comparable in levels of mixed pairings.

Material covered each day was equally divided between topics in trigonometry and logical reasoning. Learning guides provided important supporting information, and students had to solve problems within their groups. This required the students to utilize cooperative learning strategies in addition to higher order thinking. While some of the skills taught during the experience may have been introduced in the students' school curricula, the material was new to most of the students because their high schools do not offer discrete topics. Regardless, through this PBL setting, students were able to experience the material on a different level than they typically would within a traditional classroom.

\section{Instrumentation and testing}

Before the first session of the discrete mathematics experience, the students responded to a 40-question survey. This survey consisted of a selection of questions from two previously existing instruments: the Motivated Strategies for Learning Questionnaire (Pintrich and DeGroot, 1990) and the Affective Mathematics Engagement survey (Goldin et al., 2011). The goal was to address the broadest possible interpretation of engagement there. We used two related instruments with different items, specifically, the MSLQ and the Affective Mathematics Engagement Survey. We retained the similar items and added other remaining items that aligned with existing factors hypothesized in the literature, such as personal Affect, Intellectual recognition, and excitement/enthusiasm. Responses consisted of Likert ratings, with " 1 " indicating that the student strongly disagreed with the statement and " 5 " indicating that the student strongly agreed. The survey questions addressed topics such as finding solutions to problems, observations from other people and demonstration of knowledge. At the end of the final session of the discrete mathematics experience, the researchers re-administered the same survey to the students.

\footnotetext{
Analyses

The analyses were completed using SPSS 25. An exploratory factor analysis (EFA) was used to examine the underlying structure of the items on both the pretest and posttest responses individually. We used a principal component analysis with varimax rotation set to extract five hypothesized factors. Using the component matrix, the researchers initially categorized each of the 40 survey items into respective factors based on where the strongest relationship occurred. Then, the factors were analyzed for consistency among the question topics. In the event that a survey item did not seem to match the rest of the items in its factor, the researchers consulted the component matrix to assess where the next strongest relationship fell. This process was repeated until all of the questions appeared to match the rest of the
} 
JRIT

15,2

212

items in their factor. All items were retained. The EFA was repeated with the same results on the posttest items, except the variance accounted for was greater.

After each of the factors were set, reliability coefficients (Cronbach's $\alpha$ ) were calculated for each factor for both the pretest and posttest (see Table 1). Upon calculating reliability for the fifth factor, it became apparent that the factor contained misaligned items. After further consideration of the fit indexes, four items were removed to achieve a more parsimonious model. All four of the items that were deleted were items that had been reverse coded due to negative wording. Perhaps these items were difficult for students to interpret or the items were simply misaligned. Negatively worded items, historically, have posed challenges in factor analysis (Lai, 1994) and continue to be reported as causing interpretational difficulties in applied research (Heffer et al., 2021). Prior research shows that reverse coding can have a negative impact on reliability (e.g. Weems and Onwuegbuzie, 2001), further supporting the removal of these items. The remaining 36 items from the original survey all contained positive wording; therefore, the only items that were reverse coded were the four that were ultimately removed from the model.

It should be noted that although the reliability coefficient for the fifth factor, anxieties, decreased below the standard threshold for acceptable values (Taber, 2018), this change can be justified. The $t$-test comparison showed that the mean score on the anxiety factor decreased, indicating that the students experienced less anxiety after attending the camp. While this is a desired characteristic, it lowered the reliability of the factor, an issue that in this case should cause no concern. Internal consistency reliability, or Cronbach's alpha, is a numeric representation of the likelihood that if the group was retested with memory being a factor, the participants would be in the same order, not necessarily have the same score. Therefore, the difference between each score on the test is the important metric. The equation for Cronbach's alpha makes use of the standard deviation; therefore, when an intervention reduces sample variation, it reduces the variation between items, and the obtained reliability coefficient decreases (Henson, 2001).

To compare the means and standard deviations of each factor, we conducted five pairedsample $t$ tests. To examine any positive or negative changes in the factors from the beginning of camp to the end of camp, we calculated the mean differences in participants' survey responses. In this case, the differences were calculated by subtracting the mean of the factor pretest from the mean of the factor posttest. To further analyze the magnitude of change for each of the factors, we calculated the effect sizes. Specifically, we measured the effect using Hedge's $g$ because the sample size is small and this would eliminate concern over a potential Type II error (Ferguson, 2016; Lakens, 2013). Pairing these analyses provided an unbiased assessment of any changes that occurred regardless of reported statistical significance.

\section{Results}

The EFA of the students' responses to the survey showed that the survey items could be categorized into five factors: positive self-efficacy, intrinsic motivation, extrinsic motivation, completion and anxieties (see Table 2). Items containing the factor labeled "positive self-

\begin{tabular}{lcc}
\hline & & Alpha \\
Factor & Pretest & \\
\hline 1. Positive self-efficacy & 0.932 & Posttest \\
2. Intrinsic motivation & 0.807 & 0.937 \\
3. Extrinsic motivation & 0.903 & 0.705 \\
4. Completion & 0.785 & 0.852 \\
5. Anxieties & 0.683 & 0.752 \\
& & 0.497 \\
\hline
\end{tabular}

Table 1.

Reliability coefficients

5. Anxieties

0.752

0.497 
Factor 1: Positive self-efficacy

13. I realized that if I worked hard at the problem, I could figure it out

19. I wanted to teach another student something that I knew that this other student did not know

21. I helped someone see how to do the math

22. Others listened carefully to my ideas

24. I tried to impress people with my ideas about the problem

25. People seemed impressed with the ideas I shared about the problem

26. People saw how good I was at the math we did today

27. I felt smart

28. I wanted to show someone that my way was better

29. I was a lot better at math than others today

30. I argued strongly in support of my ideas

39. If I can, I want to demonstrate that I know more than most of the other students

\section{Factor 2: Intrinsic motivation}

14. As I made progress, I became more interested in understanding the math

18. I was so into my work that I tuned out things going on around me

31. I felt like the material challenged me

33. In math class, I prefer course material that really challenges me so I can learn new things

34. In math class, I prefer course material that arouses my curiosity, even if it is difficult to learn

35. The most satisfying thing for me in this course is trying to understand the content as thoroughly as possible

36. When I have the opportunity in this class, I choose course assignments that I can learn from even if they don't guarantee a good grade

38. The most important thing for me right now is improving my overall grade point average, so my main concern is getting a good grade

Factor 3: Extrinsic motivation

5. I wanted the teacher to think I am a good student

15. I felt proud about what I accomplished

16. I felt that learning the math today would benefit me or pay off for me

20. I listened carefully to the ideas of someone I was trying to help

23. I wanted people to think that I'm smart

32. I wanted to do well to show my ability to my family, friends, employer or others

37. Getting a good grade in this class is the most satisfying thing for me right now

40. I want to do well in this class because it is important to show my ability to my family, friends, employer or others

Factor 4: Completion

1. I wanted to make sure that all the required work was completed

2. The most important thing for me was getting the answer to the problem

3. I worked on getting the answer to the problem

17. I concentrated deeply on today's math problem

Factor 5: Anxieties

4 I tried to get members of my group to work to get the answer to the problem

6. I wanted to look like I was doing work even when I wasn't

7. I worried that I might get in trouble with the teacher

8. I was worried I might do something that would get me into trouble with one or more students $\mathrm{X}$

9. I paid attention to the way others were reacting to me

10. I hoped people would not pay attention to me

11. I cared more about feeling OK than about solving the math problem

12. I felt relieved when all the work was done

Note(s): *Indicates that this item (21) was relocated from another factor. X This item was removed from the model

efficacy" expressed confidence in mathematical ability as well as desire to demonstrate that level of ability to others. Items comprising the "intrinsic motivation" factor shared the common theme of general interest in the material and desire to learn rather than perform. 
JRIT

15,2

214
Items comprising the "extrinsic motivation" factor all related to the desire for approval from others or benefits outside of camp. For the factor labeled "completion," each item was connected to the desire to fulfill an assigned task. Finally, for the "anxieties" factor category, each item related to pressure or fear of negative attention.

The $t$ tests indicated students experienced positive changes over the duration of the camp (see Table 3). In particular, when comparing the total group posttest means to the total group pretest means, students reported higher levels of positive self-efficacy and intrinsic motivation. They also experienced lower levels of extrinsic motivation and anxiety and were focused less on simply completing the assigned work. In general, it is desirable for students to feel confident in themselves and seek the internal benefits of learning as opposed to focusing on attention from others, simply checking off tasks, or feeling stress or anxiety. Although the measured effects on each factor are small (see Table 3), they become increasingly noteworthy when taking into account the short time period of the project.

\section{Discussion}

The study showed that there were primarily neutral impacts with non-zero effects. What we believe the results indicate is that the use of andragogy (in this instance, self-directed learning via an informal learning environment) provided no negative effects, but the use of andragogy also did not prove to provide a markedly improved learning environment. We are cautious with these findings because several moderators could have led to our results. The students experienced positive changes in attitude over the duration of the camp. The fact that none of the differences were statistically significant may be due to small sample size (i.e. Type II error). Given that we expected our sample to be large enough to detect a 0.7 Cohen's $d$ effect, a more modest effect would have required a larger sample. It is also possible that another instrument should have been used with this type of student to be more sensitive to the types of changes under study. Just because the students fit a generic profile for the survey (i.e. grade level), their developmental level may have been better suited for a different survey structure.

Despite these factors, the measured changes could potentially imply that the informal setting of the STEM summer camp positively influenced the students' attitudes toward learning. Because the discrete mathematics experience largely incorporated self-directed learning, one of the key components of andragogy, it can be further insinuated that the honors students may have a similar preference for approaches to learning as adult learners. According to andragogical theory, as students develop into adults, their desire for selfdirected learning increases (Merriam, 2001). Though it had been previously thought that andragogy was meant as a way of distinguishing adult learning from school-age learning (Knowles, 1980), the results of the present study indicate that there may be exceptions as to when younger learners may benefit from similar instruction. After the duration of the camp, students saw an increase in self-efficacy and internal motivation as well as a decrease in anxiety and external motivation. It is possible that in this more andragogical setting, the

\begin{tabular}{|c|c|c|c|c|c|c|c|}
\hline \multirow[b]{2}{*}{ Factor } & \multirow[b]{2}{*}{$n$} & \multicolumn{2}{|c|}{ Pretest } & \multicolumn{2}{|c|}{ Posttest } & \multirow[b]{2}{*}{$M_{\text {diff }}$} & \multirow[b]{2}{*}{ Hedge's $g$} \\
\hline & & $M$ & $\mathrm{SD}$ & $M$ & $\mathrm{SD}$ & & \\
\hline 1. Positive self-efficacy & 12 & 41.3 & 10.3 & 41.6 & 11.4 & 0.3 & 0.03 \\
\hline 2. Intrinsic motivation & 8 & 31.4 & 5.5 & 31.6 & 5.2 & 0.1 & 0.02 \\
\hline 3. Extrinsic motivation & 8 & 33.2 & 5.8 & 31.9 & 6.6 & -1.3 & -0.21 \\
\hline 4. Completion & 4 & 17.4 & 2.5 & 17.4 & 2.5 & -0.1 & -0.02 \\
\hline 5. Anxieties & 4 & 14.3 & 3.4 & 13.9 & 3.0 & -0.4 & -0.19 \\
\hline
\end{tabular}

Note(s): Here $M_{\text {diff }}$ indicates posttest-pretest ( $n=$ number of items for that factor)
Table 3.

Descriptive statistics by factor 
greater sense of freedom helped students to have a more positive learning experience. Therefore, the line between pedagogy and andragogy may not be as simple as setting an age distinction; rather, the transition may occur earlier for gifted students than it does for nongifted students. As there is not much research on gifted students and adult learning, further explorations in this area may give greater insight as to how these exceptional learners can benefit from different aspects of andragogy and pedagogy.

The contribution of the factor analysis provides two important insights. First, it provided support for a more parsimonious scale and the ability to use only a particular scale that meets future research needs. Second, the first two factors had small effects and the latter two had small negative effects. The last factor, anxiety, is negative, indicating a reduction in anxiety. Taken as a whole, it is not possible to assign importance to any one factor for this study. However, interpretation of the clear distinction between the two sets may indicate that this group of students may have been more susceptible to valuing their educational independence (self-efficacy), evidenced in their increase in intrinsic motivation and decrease in perceived anxiety while devaluing extrinsic motivation and completion of work assignments. In fact, the items contributing to the completion factor may have been foreign to the students, who may not be likely work on a project to simply designate the task complete.

This study yields two potentially catalyzing insights for practitioners and teacher educators. First, gifted students may benefit from andragogical approaches as opposed to traditional pedagogical approaches designed for their grade-level peers. Specifically, developing academic tasks that emphasize principles such as self-directed learning may have potential for use in high school classrooms. Based on our findings, incorporating more activities where the student has more autonomy in their learning can enhance gifted students' learning. Second, teacher educators should make explicit reference to andragogy, explicitly use it and identify alignment in instruction that makes use of andragogy with preservice teachers, and connect how it might improve outcomes for secondary students. In order to increase effective instruction for students of all abilities, it is important to factor in instructional approaches that can empower advanced students as well. By allowing gifted students this aspect of adulthood while still in the midst of their academic career, there may be potential to improve their overall learning experience.

\section{References}

Alderman, L.R. (1928), "Public education of adults", in Biennial Survey of Education in the United States, 1928-1930, United States Bureau of Education, Washington, DC. Bulletin, 1931, Vol. I, Ch. XII No. 20, pp. 285-310.

Bailey, C.L. (2007). "Social and emotional needs of gifted students: what school counselors need to know to most effectively serve this diverse student population", paper based on a program presented at the Association for Counselor Education and Supervision Conference, 11-14 October, Columbus, $\mathrm{OH}$.

Brockett, R.G. and Hiemstra, R. (2018), Self-Direction in Adult Learning: Perspectives on Theory, Research and Practice, Routledge, London, UK.

Can, I., Koydemir, S., Durhan, S., Ogan, S., Gozukara, C. and Cokluk, G. (2017), "Changing high school students' attitudes towards mathematics in a summer camp: happiness matters", Kuram ve Uygulamada Eğitim Bilimleri/Educational Sciences: Theory and Practice, Vol. 17 No. 5, pp. 1625-1648, doi: 10.12738/estp.2017.5.0373.

Capraro, R.M. and Slough, S.W. (2013), "Why PBL? Why STEM? Why now? An introduction to STEM Project-based learning: an integrated science, technology, engineering, and mathematics (STEM) approach", Capraro, R.M., Capraro, M.M. and Morgan, J.R. (Eds), STEM Project-Based Learning: An Integrated Science, Technology, Engineering, and Mathematics (Stem) Approach, 2nd ed., Brill Sense, Rotterdam, pp. 1-5.

Autonomy of informal STEM 
JRIT

15,2
Carnicom, S. and Clump, M. (2004), "Assessing learning style differences between honors and nonhonors students", Journal of the National Collegiate Honors Council, Vol. 138, pp. 37-44.

Cross, J. (2011), Informal Learning: Rediscovering the Natural Pathways that Inspire Innovation and Performance, John Wiley \& Sons, Hoboken, NJ.

Erdogan, A. and Yemenli, E. (2019), "Gifted students' attitudes towards mathematics: a qualitative multidimensional analysis”, Asia Pacific Education Review, Vol. 20 No. 1, pp. 37-52, doi: 10.1007/ s12564-018-9562-5.

Ernest, P. (2010), "Reflections on theories of learning", in Sriraman, B. and English, L. (Eds), Theories of Mathematics Education: Seeking New Frontier, Springer, New York, NY, pp. 39-47.

Fenichel, M. and Schweingruber, H. (2010), Surrounded by Science: Learning Science in Informal Environments, National Academies Press, Washington, DC.

Ferguson, C.J. (2016), "An effect size primer: a guide for clinicians and researchers”, in Kazdin, A.E. (Ed.), Methodological Issues and Strategies in Clinical Research, American Psychological Association, Washington, DC, pp. 301-310, doi: 10.1037/14805-020.

Ghadiri Khanaposhtani, M., Liu, C.J., Gottesman, B.L., Shepardson, D. and Pijanowski, B. (2018), "Evidence that an informal environmental summer camp can contribute to the construction of the conceptual understanding and situational interest of STEM in middle-school youth", International Journal of Science Education, Vol. 8 No. 3, pp. 227-249, doi: 10.1080/21548455.2018. 1451665.

Goldin, G.A., Epstein, Y.M., Schorr, R.Y. and Warner, L.B. (2011), "Beliefs and engagement structures: behind the affective dimension of mathematical learning”, ZDM, Vol. 43 No. 4, pp. 547-560, doi: 10.1007/s11858-011-0348-z.

Heffer, T., Lundale, C., Wylie, B.E. and Willoughby, T. (2021), "Investigating sensitivity to threat with the behavioral inhibition scale (BIS) among children, adolescents and university students: the role of negatively-phrased questions", Personality and Individual Differences, Vol. 170 No. 110416, doi: 10.1016/j.paid.2020.110416.

Henschke, J.A. (2011), "Considerations regarding the future of andragogy”, Adult Learning, Vol. 22 No. 1, pp. 34-37, doi: 10.1177/2F104515951102200109.

Henson, R.K. (2001), "Understanding internal consistency reliability estimates: a conceptual primer on coefficient alpha", Measurement and Evaluation in Counseling and Development, Vol. 34 No. 3, pp. 177-189, doi: 10.1080/07481756.2002.12069034.

Kahyaoglu, M. (2013), "A comparision between gifted students and non-gifted students' learning styles and their motivation styles towards science learning", Educational Research and Reviews, Vol. 8 No. 12, pp. 890-896.

Khazanchi, P. and Khazanchi, R. (2020), "Integration of educational software in teaching gifted students in k-12 classrooms", in Ikuta, S. (Ed.), Handbook of Research on Software for Gifted and Talented School Activities in K-12 Classrooms, IGI Global, Hershey, PA, pp. 43-64.

Knowles, M.S. (1980), The Modern Practice of Adult Education: From Pedagogy to Andragogy, Association, New York, NY.

Knowles, M. (1996), “Andragogy: an emerging technology for adult learning”, Edwards, R., Hanson, A. and Raggatt, P. (Eds.), Boundaries of Adult Learning, Routledge, London, UK.

Lai, J.C. (1994), "Differential predictive power of the positively versus the negatively worded items of the Life Orientation Test", Psychological Reports, Vol. 75 No. 3_suppl, pp. 1507-1515, doi: 10.2466/2Fpr0.1994.75.3f.1507.

Lakens, D. (2013), "Calculating and reporting effect sizes to facilitate cumulative science: a practical primer for $t$-Tests and ANOVAs", Frontiers in Psychology, Vol. 4, pp. 863-872, doi: 10.3389/ fpsyg.2013.00863.

Livingstone, D. (2001), Adults' Informal Learning: Definitions, Findings, Gaps and Future Research, WALL Working Paper 21, Ontario Institute for Studies in Education of the University of Toronto, Toronto, ON. 
Marsick, V.J. and Watkins, K.E. (2001), "Informal and incidental learning", New Directions for Adult and Continuing Education, Vol. 89, pp. 25-34.

Merriam, S.B. (2001), "Andragogy and self-directed learning: pillars of adult learning theory", New Directions for Adult and Continuing Education, Vol. 89, pp. 3-14.

Neihart, M., Reis, S.M., Robinson, N. and Moon, S. (2002), The Social and Emotional Development of Gifted Children: What Do We Know?, Prufrock Press, Washington, DC.

O'Boyle, M.W. (2008), "Mathematically gifted children: developmental brain characteristics and their prognosis for well-being", Roeper Review, Vol. 30 No. 3, pp. 181-186, doi: 10.1080/ 02783190802199594.

Paris, S.G. (1997), "Situated motivation and informal learning”, Journal of Museum Education, Vol. 22 Nos 2-3, pp. 22-27, doi: 10.1080/10598650.1997.11510356.

Park, S. and Steve Oliver, J. (2009), “The translation of teachers' understanding of gifted students into instructional strategies for teaching science", Journal of Science Teacher Education, Vol. 20 No. 4, pp. 333-351.

Pintrich, R.R. and DeGroot, E.V. (1990), "Motivational and self-regulated learning components of classroom academic performance", Journal of Educational Psychology, Vol. 82 No. 1, pp. 33-40.

Pritchard, A. (2017), Ways of Learning: Learning Theories for the Classroom, Routledge, London.

Ricca, J. (1984), "Learning styles and preferred instructional strategies of gifted students", Gifted Child Quarterly, Vol. 28 No. 3, pp. 121-126.

Roberts, T., Jackson, C., Mohr-Schroeder, M.J., Bush, S.B., Maiorca, C., Cavalcanti, M., Schroeder, D.C., Delaney, A., Putnam, L. and Cremeans, C. (2018), "Students' perceptions of STEM learning after participating in a summer informal learning experience", International Journal of STEM Education, Vol. 5 No. 1, pp. 1-14.

Rogers, A. (2014), "The classroom and the everyday: the importance of informal learning for formal learning", Investigar em Educação, Vol. 2 No. 1, pp. 7-34.

Taber, K.S. (2018), "The use of Cronbach's alpha when developing and reporting research instruments in science education", Research in Science Education, Vol. 48 No. 6, pp. 1273-1296, doi: 10.1007/ s11165-016-9602-2.

Vela, K.N., Pedersen, R.M. and Baucum, M.N. (2020), "Improving perceptions of STEM careers through informal learning environments", Journal of Research in Innovative Teaching and Learning, Vol. 13 No. 1, pp. 103-113, doi: 10.1108/JRIT-12-2019-0078.

Vygotsky, Lev (1978), Mind in Society: The Development of Higher Psychological Processes, Harvard University Press, Cambridge, MA.

Warren, J.R. and Heist, P.A. (1960), "Personality attributes of gifted college students”, Science, Vol. 132, pp. 330-337.

Weems, G.H. and Onwuegbuzie, A.J. (2001), "The impact of midpoint responses and reverse coding on survey data", Measurement and Evaluation in Counseling and Development, Vol. 34 No. 3, pp. 166-176, doi: 10.1080/07481756.2002.12069033.

\section{Corresponding author}

Julia E. Calabrese can be contacted at: jcalabrese@tamu.edu

For instructions on how to order reprints of this article, please visit our website:

www.emeraldgrouppublishing.com/licensing/reprints.htm

Or contact us for further details: permissions@emeraldinsight.com

Autonomy of informal STEM 